\title{
Factors that affect menstrual hygiene among adolescent schoolgirls: a case study from Mongu District, Zambia
}

\author{
Anne Mutunda Lahme and Ruth Stern
}

\begin{abstract}
Menstruation is both a public health concern that requires hygienic management and a human rights issue that demands dignity and health. We conducted six focus groups with 51 respondents from three secondary schools in Mongu District, Western Province, in Zambia to explore factors that influence adolescent girls' understanding, experiences, and practices of menstrual hygiene. Thematic content analysis was used to identify multiple interrelated problems that stem from (1) culture and traditional practices, (2) inadequate accurate health information, and (3) poverty-related conditions. The girls faced menstruation-related inconveniences, bullying and humiliation, stress, infections, poor school attendance and performance, and dropped out of school. Policy recommendations are included.
\end{abstract}

Menstruation is a normal biological process, central to the reproductive health of postmenarchal girls and women. It is also a public health issue that requires basic prerequisites (e.g., appropriate absorbents, reliable access to water, sanitation) to manage it hygienically. Further, menstruation is a health rights issue, insofar as every person has the right to manage her menses in a dignified and healthy manner, free of insult or mistreatment.

Menstruating women are protected by multiple human rights laws and norms. The Universal Declaration of Human Rights, for example, states that "all human beings are born free and equal in dignity and rights" (UN, 1948). This norm protects people from any form of ill treatment or abuse, whether social, mental, or physical. Zambia is one of the signatory countries. The concept of a right to health has been enumerated in several international agreements. These include the International Covenant on Economic, Social, and Cultural Rights (UN, 1976), the Convention on the Elimination of all Forms of Discrimination Against Women (UN, 1979), and the Convention on the Rights of the Child (UN, 1989). The right to health includes the economic, social, and cultural conditions required to attain a universal minimum standard of well-being. The right to menstruation-related hygiene falls under the right to health. The UN General Assembly has declared access to clean drinking water and sanitation a human right and has noted that water is a prerequisite to the fulfillment of all other human rights (UN, 2010). Sanitation pertains closely to the ability of schoolgirls to manage their menses in a healthy and dignified manner. The African Charter on the Rights and Welfare of the Child similarly requires the protection of children's rights; 
signatories must provide legislative, administrative, social, and educational measures to prevent children from being abused or treated inhumanely (OAU 1990).

Girls' and women's reproductive health, including menstruation, is therefore encompassed in these rights (UNFPA \& DIHR, 2014). These are fundamental rights, to be protected in accordance with moral principles, norms, and standards (James et al., 2013). Zambia, which is party to these agreements, has a duty to elect and pursue policies to eliminate discrimination on the basis of menstrual status.

However, there is a global tendency for governments to disregard such obligations; consequently, these health rights are often infringed. In many countries, including Zambia, the right to the appropriate conditions for reproductive health is challenged by numerous factors. These include the availability of accurate information, guidance, and support; religion- and culture-based gender norms and values; and the impact of poverty (Warenius et al. 2007). The dignity of vulnerable people, in this case menstruating schoolgirls, is threatened by their states' and institutions' failure to recognize and respond to their reproductive health needs (Mann et al. 1994).

\section{Information and guidance}

Adolescent girls of many countries lack accurate health information at a time when they need to prepare mentally and physically to manage their periods appropriately (Mahon \& Fernandes, 2010: Nagar \& Aimol, 2011). Studies of similar population groups in Africa and Asia highlight the relevance of early, sensitive, and formal education in reproductive health, including the menstrual cycle. The aim of this guidance is to prevent misconceptions, build girls' confidence and self-esteem (Adinma \& Adinma, 2008; Lawan, Nafisa, \& Aisha, 2010; Warenius et al. 2007), and prepare girls emotionally and psychologically so as to reduce stress and embarrassment (Anjum et al. 2010; Onyegegbu, 2011). Therefore, if we incorporate menstrual hygiene into school curricula and home education, girls can be empowered to manage their menstruation properly right from the beginning, thus enabling them to live healthy and dignified lives (Nagar \& Aimol, 2011; Thakre et al. 2011).

\section{Culture and traditional practices}

In many countries across the globe, including Zambia, coming of age is associated with cultural prejudices and misconceptions. For example, Sommer's (2008) study of girls' experiences of menstruation in Kilimanjaro, northern Tanzania, revealed that social pressure is frequently employed to force girls, once they have reached reproductive age, to enter into early marriages and, consequently, to quit school. Similar findings were reported from southern India, where the social dimensions of the ritual celebrations of menarche and menstruation include strict rules of seclusion with the girl confined to a hut or room, unable to go out unaccompanied or to touch particular food items (Narayan, Srinivasa, Pelto, \& Veerammal, 2001).

The impact of traditional practices of coming-of-age-related cultural rituals were also described in a study (Pillitteri, 2011) undertaken in Malawi, where, among certain ethnic 
groups, the puberty rituals require conditions of separation. The menstruating girls are no longer able to share their parents' or families' bath shelters or associate with friends who have not reached menarche. Furthermore, once they reach menarche, they are considered ready for marriage. The consequences of these practices, in addition to their many physical and psychological hazards, is a high risk of HIV and other sexually transmitted infections, unwanted pregnancies, and the accordant threat of illegal and, therefore, unsafe abortions (Pillitteri, 2011).

Cultural biases have also been shown to have policy implications. In their classic study, Bharadwaj and Patkar (2004) highlighted that the lack of policy debate, action, and investments regarding menstrual hygiene and management were widespread in developing countries, especially in Africa and Asia, mainly due to culturally based prejudices. They recommended policy advocacy, investments, and action toward better health education and improved facilities so that girls and women can manage their menstrual needs adequately. Many others (e.g., Winkler \& Roaf, 2015) have published similar findings and recommendations.

\section{The impacts ofpoverty}

The influence of the socioeconomic status of a girl's family on menstrual hygiene practices is well documented (Kumar \& Srivastava, 2011; Nagar \& Aimol, 2011; Omidvar \& Begum, 2010; Shanbhag et al. 2012). Negative mental and emotional impacts can also ensue from the families' poor socioeconomic condition (Adinma \& Adinma, 2008; Pillitteri, 2011).

Studies of poverty in developing countries have demonstrated the negative impact of the lack of services and facilities required for menstrual hygiene on girls' access to education (Pillitteri, 2011; Sommer, 2008). Research conducted in Egypt and Malawi showed that inferior sanitation facilities in schools encroach on girls' rights to privacy and cause stress and depression, which, in turn, affect their academic performance (El-Gilanya et al. 2005; Pillitteri, 2011). Pillitteri (2011) documented that poor menstrual hygiene and sanitation management in schools in Malawi, which fail to reach the World Health Organization's minimum standard toilet/student ratio, contribute to girls' high rates of absenteeism. The lack of privacy was a particular concern noted by one of Pillitteri's (2011, p. 9) respondents, who stated, "Nobody cares about the toilets here ... We have no doors and [no] water. It's better to stay at home when you menstruate."

Lack of, or inadequate, facilities were also reported in Kilimanjaro, Tanzania (Sommer, 2008), where most of the toilets for girls in schools were gender-unfriendly. ${ }^{1}$ Many of Sommer's Tanzanian participants feared staining their dresses, which resulted in mental stress; hence they preferred to stay at home during menstruation.

\footnotetext{
1 The term gender-friendly bathrooms (also known as "girl-friendly bathrooms" and "gender-" or "girl-friendly latrines") has no universal definition. However, working understandings of the terms include (1) functioning toilets, (2) separate latrines from boys, (3) soap and water for washing, (4) free or subsidized sanitary napkins, (5) privacy, and (6) safety from assault and harassment (Mooijman, 2006).
} 


\section{Discrimination}

Gender discrimination associated with sexist sociocultural beliefs and gender-unfriendly policy environments pose further barriers to girls' education by affecting their school attendance. Research from both sub-Saharan Africa and Asia has indicated that the lack of understanding of menstruating girls' needs can result in bullying behavior against menstruating girls by male schoolmates and male teachers (Fernandes, 2008; Kirk \& Sommer, 2006; Pillitteri, 2011; Sommer, 2008).

\section{The situation in Zambia}

In theory, Zambia is conforming to the standards required to support women and girls during menstruation. It is a signatory to the relevant international and regional declarations and conventions. The Ministry of Local Government and Housing (MLGH) instituted the National Rural Water Supply and Sanitation Programme (NRWSSP) in 2007, and in 2010 a Hygiene Component was added. However, this commitment has not been translated into reality. In the majority of cases, girls' and women's sanitation demands are not considered when new sanitary facilities (e.g., latrines) are designed and constructed, and there remains a lack of adequate design and construction standards for homes, schools, and public toilets (Zambia Public Health Act/ZPHA CAP 295). In addition, the Zambian Preventive Health Programme, which came into being in 1964, fails to address the special sanitation demands of girls and women and neglects to address menstruation in schools, at health facilities, and at the community level.

\section{The present study}

The present study is an exploratory qualitative study undertaken in 2013 into the factors that impact the menstrual hygiene of adolescent girls in Mongu District in the Western Province of Zambia. The first author's interest in the study topic was triggered by her work as a sanitation and health officer in rural Zambia, which included dealing with school sanitation. During that time, it became clear to her that authorities did not adequately address water, sanitation, or adolescent girls' menstrual hygiene and that their failure to do so was an infringement of girls' human rights.

\section{Method}

\section{Participants}

The sample was 51 girls, ages 16-20, who had reached menarche. The girls were from three secondary schools: one government-sponsored and two mission schools. Two offered both boarding and day school facilities; the third was a day school. The girls were selected by a process of purposeful sampling aimed at girls who could provide in-depth and rich information about their experiences. Girls who had not reached menarche, were pregnant, or had given birth were excluded.

The study was conducted in Mongu District, one of the seven districts in the Western Province of Zambia; it is situated 620 kilometers to the west of Lusaka, the capital city. The district covers an area of 10,075 square kilometers. The girls belonged to the Lozi ethnic group, which numbers approximately 575,000 people in western Zambia. The poverty level in Mongu 
District is estimated at 62\% (ZDHS, 2007). The Lozi society is highly stratified, patriarchal, and traditionalist (Appiah \& Gates, 2010).

\section{Procedure}

The research tool for the study was focus group discussions (FGDs). We preferred these to individual interviews, as they are known to create a trustworthy forum for exchanging views and learning about shared norms and group experiences (Blanche, Durrheim, \& Painter, 2006; Brink \& Van Rensburg, 2006; Liamputtong \& Ezzy, 2005). We conducted six FGDs, two in each school, with each group comprising 8-10 participants. The data were collected from February 12-15, 2013. The FGDs were conducted in both English and Silozi, the local language. They were audiotaped, transcribed, and translated into English as necessary.

Thematic content analysis was used to analyze the data. Data from all the transcripts related to the classified patterns were identified and placed in relevant themes. Thereafter, related patterns were combined, listed as subthemes, and their similarities identified (Elo \& Kyngäs, 2008). Member checking, where the conclusions were tested by checking the data with both the participants and a research assistant, helped to validate the results. In cases of misunderstandings or doubts, participants were invited to check and validate findings. The recommendations and conclusions were reached in conjunction with the participants.

Data triangulation was carried out by means of two approaches. The first was data source triangulation, in which data were collected from the three schools and checked for similarities and differences. The second compared the data with relevant cases in the literature. We also used reflexive awareness; we recorded all events during the FGDs and entered them into a diary to reduce the risk of bias. The observations were also compared with those of an assistant researcher who was hired and trained to provide support during the FGDs. To improve trustworthiness, peer debriefing was conducted by asking other researchers to read the transcripts and compare the themes that were derived from the scripts.

Ethical approval for the study was obtained from the relevant authorities in Zambia and South Africa. Permission was granted by the girls' parents or guardians, and the girls were assured of anonymity. They were also told they could withdraw from the study at any stage.

\section{Results}

The participants raised a range of issues related to the emotional and practical difficulties they encountered when they started menstruating. We anticipated that this would be the main focus of the FGDs. However, it soon became clear that these issues are interrelated, and that, in combination, they were significantly more life-changing than would be expected from a normal biological function. The girls' early comments focused on the lack of information about menstruation, the reasons for that lack, and some of its immediate implications. However, as the FGDs progressed, the girls described the impact of their culture, traditions, and myths, as well as the impact of poverty. Soon, it became quite clear that their lives were 
profoundly affected by what, under other circumstances, could simply be a natural passage to adulthood.

\section{The absence of accurate information}

One important finding is that, before they reached menarche, many of the girls were kept in the dark about menstruation and related issues of reproductive health. They were either not adequately informed, or not informed at all, about the biological changes they would soon experience, nor were they made aware of the psychological processes they would face. This is a result of the many restrictions imposed by aspects of their culture, including certain beliefs and taboos associated with menstruation.

The girls in all of the focus groups talked openly about how surprising the experience of menarche had been for them. Many used the FGDs as an opportunity to voice their frustrations about having been exposed to such a shocking experience without adequate preparation. For example, one girl, and then another, said the following:

I came to know about it when I started menstruating. I had to ask my mother whether I was sick or bewitched [laughter].

Yes. I thought I had hurt myself. I also started crying and went to Mom ... I was terrified as I did not know what was happening to me.

These statements demonstrate how inadequate information about menstruation prior to menarche led to confusion, anxiety, and, in some cases, sheer terror. The girls broadly agreed that providing information at school is essential. As one explained:

Yes. I personally feel it is very important to learn about reproductive health in all classes, because had my mother not been at home at that time ..., I don't know what I could have done.

The FGDs also revealed that girls attending the mission schools, although not fully knowledgeable, knew more about the process of menstruation than did girls attending the government school. The government schoolgirls deplored their lack of knowledge, whereas the mission schoolgirls demonstrated a slightly better knowledge level, albeit a biological awareness only. For example, one girl reported:

They teach about the anatomy of the uterus, the process of menstruating, of fertilization of the eggs, and how eggs move from the ovary into the uterus. They also talk about the importance of keeping yourself clean by bathing and changing of pads, regularly.

The main reason for the different knowledge levels is that, in Zambian government schools, menstruation and reproductive health are not part of the curriculum. This information is not taught at the primary level at all, and, at secondary level, it is covered only in biology and home economics, neither of which are compulsory subjects. Although the Zambian government is a signatory to treaties that govern and protect the rights of girls and women, 
implementation is inadequate. This pertains especially to the reproductive health program. The lack of accurate and timely information about the menstrual process is related to the conservative cultural traditions of Zambia's Western Province, which impacted all of the girls, regardless of where they went to school. Their communal lives are typically guided by rules and taboos, including the expectation that menstruation and menarche are generally inappropriate topics in homes or with close family members. Among Lozi families it is quite often the grandmothers who talk to the girls about menstruation. If there is no grandmother, or the grandmother is not willing to talk about it, then the girls must lean on their friends. As one girl noted: "Mostly we hear about it from friends and at school, when those who have started their periods are discussing it. It is rare to discuss such issues at home as it is a taboo."

Close family members do not seem to be very supportive of girls and their menstrual experiences. The girls reported a lack of basic assistance regarding menstruation and menstrual hygiene from family members. Some girls reported negative experiences with close members of the family when they experienced problems such as abdominal pains. For example, one girl said: "When you have menstrual pains and sleep, elders at home say you are lazy."

As the FGDs progressed, a correlation between educational level and menstrual knowledge emerged. Despite the general taboo, there were two examples where families did discuss such issues with their daughters. In both cases the mothers were formally educated. In these families, parents also provided moral support to the girls when they faced problems. A girl from one of these families shared: "My mother who is a nurse used to tell me and all my sisters that when you start seeing blood on your pants or stain yourself, do not be afraid ... So when I saw my first blood I was really not afraid.”

The majority of fathers were described as not talking to their daughters about menstruation, and vice versa, and this applied as well to other male family members. One girl described a high degree of ignorance mixed with intolerance by a male family member: "When I was having my menstruation that day, I was not feeling well and started vomiting. He (my brother) forced me to go the hospital ... At the hospital he told the nurses, I think this girl is pregnant, please check her properly. I felt very humiliated."

\section{The impact of culture and tradition}

When the girls were asked why menstruation is kept secret, they could not give a concrete reason. They reported that they were told by elders that it is a taboo and therefore not to be discussed. They saw these deeply ingrained cultural norms as the cause of substantial barriers to their knowledge of their bodily functions, and they discussed how the norms prevented girls from being able to manage their monthly periods in a dignified and hygienic way. The cultural traditions also included practices that some girls found disturbing. For instance, many girls knew about taboos regarding food preparation. One girl explained: "Elders say that when a girl is having her period ... you may not add salt to food, as it will cause other people to start coughing. They might have TB or pneumonia. Especially men.” 
However, not all the respondents believed these myths. One girl, for example, puzzled over what to believe: "Madam, some of these (myths) are really hard to understand because we also learnt ... to have TB you must come into contact with the TB bacteria. And this disease (TB) is airborne. So ... you wonder how it is associated with menstrual blood.”

However, there were other myths that they many of them firmly believed. This included the view that menstrual blood can be misused for ritual purposes, such as in witchcraft practices that can result in sterility. As one girl offered: "Some people say witches can harm you if they come across (your) menstrual blood.... you have prolonged periods or other complications ... they can make you sterile."

Upon hearing this statement, every girl in that particular FGD nodded in agreement; thus these girls see the myths as widespread in the traditional culture of this part of Zambia. These are some of the firmly held, normative, widespread beliefs that restrict and, in some instances, frighten the girls.

The traditional culture of Western Province is very strong, and rituals pertinent to girls' coming of age were of high importance in the FGDs. The ritual that the girls found most stressful was their initiation into adulthood. None of the girls who had undergone the ritual (called sikenge) liked it; they found it humiliating and even traumatic. As one of the girls who was initiated at her home said: "It is embarrassing, especially if there are visitors at home ... you really feel bad.”

Several girls shared their understandings of the initiation ritual. They explained that it involves being separated from family members and friends and kept in isolation for a varied period of time (e.g., 3 weeks -6 months), which results in missing school during the initiation period. Our participants reported cases where girls, after having been absent from school for so long, dropped out of school altogether. Furthermore, upon completion of the initiation period, many of the girls said that they had to end friendships that were built up from girlhood, as it is expected that pre-menarchal girls should not associate with post-menarchal girls. In addition, as post-menarchal girls are expected to be grown-up women, after initiation girls are required to change their dress code, a source of intimidation and frustration. One girl explained: "You lose some of your old friends ... you should not play or mix with girls who have not started menstruating. You are not allowed to wear short dresses, skirts, or trousers." The initiations are overseen by elder women, who introduce the girls to various issues that denote the end of childhood and the beginning of womanhood. During the initiation period, the elders, called initiation counselors, teach what our participants described as valuable practical lessons, including how to manage their menstruation. These were often based on traditional puberty rituals, which the majority of the girls found distressing. Some of these rituals promote unhygienic practices. For example, in some ethnic groups, the girls are forbidden to bathe for the duration of the initiation period. Other lessons were about how to look after a husband, how to have sex, and how to perform in bed. The latter included being inspected by the initiation counselors, including their private parts, with a view to their 
physical readiness to have sex. The girls believed they were being prepared for marriage, which they did not like. As one girl reported:

What we hear from people is that when you are in sikenge [initiation period] they teach you how to take care of yourself and your husband [laughter]. In other words, they prepare you to go into marriage [laughter and shyness]. The community perceives that when a girl starts menstruating she is ready for marriage.

If the girls are correct, preparation for marriage may be the core reason why girls' initiation has developed as a cultural tradition over decades or maybe even centuries, although exploring the purposes of the ritual is beyond the scope of this article.

The girls had much to say about the impact of the initiation ritual. Many reported that what they learned during their lessons tempted them to experiment with sex. One girl opined:

What they [the girls] are being taught there, some girls immediately they come out of the initiation ceremonies they start doing ... like having sex ... because of what you are taught during that initiation period [laughter]. A lot of girls after initiation they become pregnant or go into early marriages.

Whether and to what extent the initiations actually cause or inspire sexual activity has yet to be studied systematically. The fact remains, however, that the initiation rituals are perceived as motivating otherwise sexually inexperienced girls to try sex.

\section{Impact of poverty}

Another important finding is the extreme difficulty the girls experienced in achieving and maintaining good standards of hygiene while menstruating. This was caused by both their own family's poverty and the resource-poor schools they were attending. This difficulty was a source of embarrassment and distress to the girls.

The girls' poverty became apparent when they disclosed that the majority of their families could not afford to buy menstrual pads. Hence they had to use old clothes and blankets torn into rags (which can be reused several times), and sometimes toilet paper, to absorb menstrual blood. Another indication of poverty for those girls who lived far from school is that they could not afford the bus fare to and from home on a daily basis, and so they had to walk. The girls said that walking these long distances was burdensome on a normal day, especially in the rainy season, but became especially onerous, and even traumatic, on the days they had heavy flows. As one girl shared: "Walking for a long distance with a pad or menstrual cloth on causes friction, so when you are menstruating you just stay at home."

The girls also mentioned inadequate water supply, poor and gender-unfriendly sanitation facilities, and the nonexistence of facilities for drying their washed menstrual materials. As one of the girls said, and the others smiled and nodded in agreement, "Us girls in the boarding [school], we wash our menstrual cloth at night and dry them under our mattresses." 
The inadequate and irregular water supply posed serious obstacles to maintaining healthy standards of hygiene during menstruation. This included the girls having to walk long distances to look for water, particularly when the nearest hand pump was in disrepair-a regular occurrence. In those situations, they must fetch water at the nearest river and store it in buckets. They also described having to wake up inordinately early in the morning to draw water for bathing, wasting a lot of time they could better use for studying. As one girl explained:

What we experience here at [boarding] school is that we don't have adequate water supply and our school has no running water ... It is very difficult to maintain a high standard of hygiene, maybe you only wash once a day and that's at night.

None of the three schools were in possession of adequate sanitation facilities for girls, including facilities for the girls to wash and to dispose of their used menstrual absorbents. This lack led many girls at day schools to stay at home during menstruation. One remarked that boys have more suitable toilet facilities than girls, for the simple reason that the toilet design accommodates boys, but not girls. She elaborated:

Our toilets do not have facilities for bathing. I don't know why this is so if you go into the boys' toilets you will find urinals, which makes boys urinate well without difficulties ... but us girls have no place for washing, no bin for disposing of pads. This is very unfair.

\section{Health impacts}

The aforementioned conditions contribute to a long list of potential health problems, both psychological and physiological. The majority of the participants in the FGDs reported mental and emotional stress during menstruation when at school. The girls reported difficulties concentrating on learning, as they are distracted not only by their physical discomfort but also by concerns about leaks, mess, exposure, and embarrassment. Due to their mental stress, they know that they risk poor academic performance, including possibly failing their exams. The girls also complained about frequent abdominal pains, vomiting, and dizziness during menstruation. Most participants in the FGDs spoke about the negative consequences of the unhygienic practices applied to managing their menstruation, such as not changing menstrual absorbents, not washing regularly, or using unhygienic materials. One girl explained:

If you don't wash and change your sanitary pads regularly you can have rashes and bruises. ${ }^{2}$ It's very common to feel itching when you are using old rags or pieces of blankets ... you feel very uncomfortable, but madam we have no choice.

\footnotetext{
${ }^{2}$ It is likely that such bruises are caused by injuries from lumpy and ill-fitting menstrual products. Further research is needed to establish the actual causal relationships between choice of menstrual absorbent and health risks (see Sumpter \& Torondel, (2013).
} 


\section{Gender discrimination}

Gender discrimination did not appear as a separate issue during the FGDs. Instead, it emerged as a crosscutting multidimensional factor. As mentioned earlier, due to traditional and cultural beliefs, the topics of menstruation and menstrual issues are not typically discussed with male family members. The girls interpreted this as gender discrimination through silence. At school, gender discrimination was more explicit, as girls' needs were clearly not considered: a lack of privacy for washing, inadequate water supply, and the lack of bins and incinerators for disposing of used menstrual materials. One girl recalled a time when she accidently messed herself and was required by her (male) teacher to report on her misfortune in writing as a punishment for being careless. She recalled: "You can even write a report on that. You know, especially the male teachers, I don't think they understand that when you mess yourself up it is an accident."

Events such as these have a negative impact on the girls' psyches and add to their feelings of gender-based discrimination.

By far the greatest intimidation the girls experienced, however, was the behavior of their male schoolmates. The girls in the FGDs described the boys in their classes as ignorant "bully-boys" who take pleasure in teasing, ridiculing, and harassing the girls when they are menstruating. They therefore live in persistent fear that their male classmates might detect their menstrual status, which leads to loss of concentration and self-esteem. One girl stated: "The boys ... will be laughing at you ... wherever you pass they will be laughing and talking about you." As another girl put it: "You will make yourself very small. Sometimes ... this can affect your academic performance."

\section{Discussion}

Our study captured adolescent girls' voices as they described how their human rights were violated in many interrelated ways. Their experiences closely reflect the findings of earlier researchers, such as Anjum, Zehra, Haider, Rani, Siddique, and Munir (2010); Mohan and Fernandes (2010); Pillitteri (2011); Sommer (2008); Warenius, Pettersson, Nissen, Hojer, Chishima, and Faxelid (2007); and Tjon ATen (2007)

Common experiences expressed by the participants-and supported by the literatureinclude being denied timely information on reproductive health issues, being forced into seclusion with their mobility curtailed during menstruation, and the lack of adequate physical facilities and appropriate menstrual absorbents. High levels of stress were reported by the girls and were reinforced by perceptions of male teachers and male schoolmates' harassment and ridicule. Perhaps the greatest infringement of the girls' human rights is that many of them were forced to miss classes or even drop out of school after they reach menarche. This is a violation of their right to education and contradicts various UN conventions, including the Convention on the Elimination of All Forms of Discrimination Against Women (UN, 1979). In

the Lozi culture, menstruation is to be kept silent and hidden. This culture of silence, as described by the girls, leads to misunderstandings and misinformation about menstruation and the menstrual process among men and-most important- among pre-menarchal girls. 
Through their participation in the FGDs, the girls soon recognized that these prohibitions compounded the infringement of their rights. They demanded guidance and support regarding coming of age and reproductive health issues. They wanted to be psychologically prepared, to develop self-esteem, and to understand the physiological changes of their entry into womanhood. In brief, they wanted to be enabled to lead dignified lives.

The strong tradition of initiation is still widely practiced among the Lozi people. The girls who had undergone initiation found the ritual an embarrassing and intimidating experience. They were also distressed by their separation from family members and friends and the restriction of their movements, including the inability to attend school, and the permanent changes in behavior expected of them.

A major disappointment for the participants was the community's expectations of them post-initiation, as this reinforced their sense of a loss of independence and self-power. What could have been a valuable opportunity for health and hygiene education and emotional support instead became evidence of a change in their lives from girl to potential wife, something they found particularly terrifying at their young age. The impact on their sexuality was also confusing, and some girls posited that incomplete sexuality education may serve as a temptation to experiment with sex as a way to fill in the gaps in their knowledge.

The impact of poverty was also profound, as reflected in numerous other studies (Kumar \& Srivastava, 2011; Nagar \& Aimol, 2011; Omidvar \& Begum, 2010). The inability to access hygienic absorbents resulted in discomfort and the possibility of infections; inadequate toilets and shower facilities often meant a lack of privacy. This in turn made it difficult for the girls to stay focused on their lessons. Concerns about the consequences of poor menstrual hygiene and not being able to do anything about it has also been shown in other studies to result in anxiety, emotional stress, and embarrassment (El-Gilanya, Badawib, al Fedawyb, \& S., 2005; Pillitteri, 2011).

The girls' descriptions of gender discrimination permeated the FGDs. They believed that its foundation is the menstrual taboo. At home, this manifested in the girls not being allowed to mention menstruation in the presence of men and boys, who were unaware of or inconsiderate of the girls' menstrual experiences. At school, this manifested in the lack of support by teachers, especially male teachers, who, according to the girls, were unaware or ignorant of their needs and problems, and by the behavior of their male schoolmates that led the girls to live in constant fear of being ridiculed and harassed. The girls were clear that what should be a normal event could and did easily often turn into a nightmare. This confirms the results of previous research, which has demonstrated the impact of gender discrimination on menstruating adolescents (Fernandes, 2008; Pillitteri, 2011; Sommer, 2008).

\section{Limitations}

Each study has its limitations. In this case, the small sample and the focus on the Western Province of Zambia do not allow results to be generalized, although many of the study's findings were confirmed by other studies in other developing countries. This limitation highlights the 
need for additional studies in other areas of Zambia, which would enable a better understanding of the negative impacts of poor menstrual hygiene on the physical and mental health and well-being of girls, on their education, and their futures in general.

\section{Policy recommendations}

We recommend that solutions be sought through a community setting, which would involve improving the broader socioeconomic, cultural, and environmental conditions. All stakeholders (i.e., parents, teachers, children/youths both male and female, governments, and communities) should cooperate to generate context-specific solutions for creating safe menstrual care and dignified conditions for adolescent girls. Such a process has the potential to build a supportive environment for girls to manage their periods in an appropriate manner in school and at home, free of gender discrimination and threats to their physical and mental well-being.

To create an enabling environment in schools and communities, stakeholders must teach and develop a close dialogue with girls and teachers of both genders. The Ministry of Education (MoE) should work together with the Ministry of Gender (MoG), Ministry of Health (MoH), and Ministry of Chiefs and Traditional Affairs (MOCTA) through the House of Chiefs to promote girls' reproductive rights in schools and communities. Reproductive health subjects should be introduced early in schools, where relevant information is also given to boys. Rules of good behavior for boys toward girls must be elaborated and enforced.

Traditional leaders, through the MOCTA, must promote increased awareness of menstruation and menstrual hygiene in the communities, as well as encourage that the traditional initiation curricula be reviewed and amended. Mediation and involvement must be undertaken at the community level where religious and civic leaders, traditional leaders, and parents must promote increased awareness of menstruation and menstrual hygiene issues through the Parents-Teachers Association and provide practical assistance as necessary.

As stated in the African Charter on the Rights and Welfare of the Child (OSU, 1990), MOCTA should also work with $\mathrm{MoH}$ to develop a deliberate policy to provide information about safer sex during initiation, to enable participants to make informed choices regarding their sexuality, and to prevent early pregnancies, marriages, HIV infection, and other STIs. This will require Initiation Counselors to have relevant safer sex counseling skills.

The Ministry of Local Government and Housing (MLGH) must mobilize relevant stakeholder ministries (e.g., MoE, MoH) to coordinate their work on the menstrual hygiene and reproductive health of adolescent schoolgirls, either by establishing a joint task force or by revitalizing the existing National Sanitation Working Group. At the national level, MLGH must incorporate menstrual hygiene and management into the National Sanitation and Hygiene Strategy.

The MoH, through the Ministry of Legal Affairs, must implement the relevant legislation [PHA CAP 295 of the laws of Zambia, Section 75, Drainage and Latrine Regulation, Reg. 81, 
Subsection a (i)] to integrate management of menstruation and menstrual hygiene in the design and equipment of girls' school toilets. The MoE, through school-led total sanitation initiatives, must design toilets that are user-friendly for girls, as well as develop the capacity of teachers (both male and female) to cope better with the menstrual hygiene needs of adolescent girls in schools.

All of the above will require comprehensive, coordinated, and aggressive advocacy for policy changes at national, local, and community levels to protect the health and rights of menstruating schoolgirls in Mongu District, Zambia.

\section{Conclusion}

In 1948, the WHO defined health as "a state of complete physical, mental and social well-being and not merely the absence of disease or infirmity." Health is also a human right, and girls are entitled, if not to enjoy their menstrual periods, at least to experience them in a dignified manner, without mental and physical stress and without threats to their health. Furthermore, in 1989 through the UN general assembly on protection of children's rights, a convention was issued in which it was agreed that "each government has a responsibility to respect, protect and fulfill children's rights. When countries ratify the convention, they agree to review their laws relating to children" (UNICEF, 1989, p. 1). However, as our study has shown, these rights are put at risk by lack of information, by inadequate menstrual materials and sanitation, and by some traditional rites. Our study also revealed that, according to the girls, the high degree of emotional stress caused by these determinants can negatively affect their academic performance. Girls reported that some were unable to endure the stress and hence were forced to terminate their school careers. These violations of menstruating girls' dignity infringe on not only their right to health but also their right to education free of gender-based discrimination, and thus demonstrate the need for aggressive policy interventions. 


\section{References}

Adinma, E. E., \& Adinma, J. I. B. (2008). Perceptions and practices on menstruation amongst Nigerian secondary school girls. African Journal of Reproductive Health, 12, 74-83.

Appiah, K. A \& Gate,. Africana: The Encyclopedia of African (2010) Oxford University Press.

Anjum, F. Zehra, N., Haider, G. Rani, S., Siddique, A. A., \& Munir, A. A. (2010). Attitudes toward menstruation among young women. Pakistan Journal of Medical Sciences, 26, 619-622.

Blanche, M. T., Durrheim, K., \& Painter, D. (2006). Research in practice: Applied methods for the social sciences. Cape Town, South Africa: UCT Press.

Brink, H., Van-Der-Walt, C., \& Van Rensburg, G. (2006). Fundamentals of research methodology for health care professionals (2nd ed., pp. 109-121). Cape Town, South Africa: Mills Litho.

Bharadwaj, S., \& Patkar, A. (2004). Menstrual hygiene and management in developing countries: Taking stock. Mumbai, India: Junction Social.

El-Gilanya, A., Badawib, K., \& al Fedawyb, S. (2005). Menstrual hygiene among adolescent school girls in Mansoura Egypt. Reproductive Health Matters, 13, 193-154.

Elo, S., \& Kyngäs, S. H. (2008). The qualitative content analysis process. Journal of Advanced Nursing, 62, 107-115.

Fernandes, M. (2008, November). The untold story-menstrual hygiene: Issues of awareness and practices. Paper presented at the 3rd South Asian Conference on Sanitation, Delhi, India.

James, N, Thomas, P, Smith, M. B. E., \& Wenar, L. (2013). Stanford Encyclopedia of Philosophy, Human Rights.

Kirk, J., \& Sommer, M. (2006). Menstruation and body awareness: Linking girls' health with girls' education. Royal Tropical Institute (KIT), Special on Gender and Health (pp. 122). Amsterdam, The Netherlands. Retrieved from http://www.susana.org/ resources/documents/default/2-1200-kirk- 2006menstruation-kit-paper.pdf

Kumar, A., \& Srivastava, K. (2011). Cultures and social practices regarding menstruation among adolescent girls. Social Work in Public Health, 26, 594-604.

Lawan, U. M., Nafisa, W. Y., \& Aisha, B. M. (2010). Menstruation and menstrual hygiene among adolescent school girls in Kano, north-western Nigeria. African Journal of Reproductive Health, 14, 201-207.

Liamputtong, P. R., \& Ezzy, D. (2005). Qualitative research methods. Sydney: Oxford University Press.

Mahon, T., \& Fernandes, M. (2010). Menstrual hygiene in South Asia: A neglected issue for WASH (water, sanitation and hygiene) programmes. Gender \& Development, 18, 99113.

Mann, J. M., Gostin, L., Gruskin, S., Brennan, T., Lazzarini, Z., \& Fineberg, H. V. (1994). Health and human rights. Health and Human Rights Journal, 1, 6-23. doi:10.2307/4065260

Ministry of Local Government and Housing (MLGH). (2017). National rural water and supply and sanitation programme (2006-2015). Lusaka, Zambia: Government Printers. 
Mooijman, A. (2006). Girl-friendly toilets for schoolgirls: Helping adolescent girls. The Hague, the Netherlands: IRC. Retrieved from http://www.ircwash.org/resources/girl-friendly-toilets- $\quad$ schoolgirls-helpingadolescent-girls

Nagar, S., \& Aimol, R. K. (2011). Knowledge of adolescent girls regarding menstruation in tribal areas of Meghalaya. Studies of Tribes and Tribals, 8, 27-30.

Narayan, K. A., Srinivasa, D. K., Pelto, P. S. V., \& Veerammal, S. (2001). Puberty rituals, reproductive knowledge, and health of adolescent girls in South India. Asia-Pacific Population Journal, 16, 2.

Onyegegbu, N. (2011). Menstruation and menstrual hygiene among women and young females in rural eastern Nigeria. Retrieved from http://www.stanonline.org/journal/pdf/JSTAN-Nkadi\%202011.pdf Omidvar, S, Begum, K. Factors influencing hygienic practices during menses amongst girls from South India. A cross sectional study. International Journal of Collaborative Research on Internal Medicine \& Public Health. (2010). 2 (12): 411-423.

Organization of African Unity (OAU). (1990, July 11). African Charter on the Rights and Welfare of the Child. [CAB/LEG/24.9/49.] Retrieved from http://www.acerwc.org/download/african-charter-on- the-rights-and-welfare-of-thechild/?wpdmdl $=9406$

Pillitteri, P. S. (2011). School menstrual hygiene management in Malawi: More than toilets. Sanitation and Hygiene Applied Research for Equity. Retrieved from http://r4d.dfid.gov.uk/pdf/outputs/sanitation/menstrualhygienemanagement malawi . $\mathrm{pdf}$

Shanbhag, R. D., Shilpa, R., D'Souza, N., Josphine, P., Singh, J., \& Goud, B. R. (2012). Perceptions regarding menstruation and practices during menstrual cycle among high school adolescent girls in resource limited setting around Bangalore City, Karnataka, India. International Journal of Collaborative Research on Internal Medicine \& Public Health, 4, 1353-1362.

Sommer, M. (2008). Menstruation and school attendance in sub-Saharan Africa: Girls' experiences of menstruation and schooling in urban and rural Kilimanjaro, in northern Tanzania. Retrieved http://2008youthconference.blogspot.com/2008/04/menstruation-and-schoolattendance.htm

Sumpter, C., \& Torondel, B. (2013). A systematic review of the health and social effects of menstrual hygiene management. PLoS ONE, 8(4), e62004. doi:10.1371/journal.pone.0062004

Thakre, B. S., Thakre, S. S., Reddy, M., Rathi, N., Pathak, K., \& Ughade, S. (2011). Menstrual hygiene: Knowledge and practice among adolescent school girls of Saoner, Nagpur District. Journal of Clinical and Diagnostic Research, 5, 1023-1033.

Tjon ATen, V. (2007). Menstrual hygiene: A neglected condition for the achievement of several Millennium Development Goals. Brussels, Belgium: Europe External Policy Advisors.

United Nations (UN). (1948, December 10). Universal Declaration of Human Rights. Retrieved from http://www.refworld.org/docid/3ae6b3712c.html 
United Nations (UN). (1979, December 18). Convention on the Elimination of All Forms of Discrimination Against Women. Retrieved from http://www.refworld.org/docid/3ae6b3970.html

United Nations (UN). (1989, November 20). Convention on the Rights of the Child. Retrieved from http://www.refworld.org/docid/3ae6b38fo.html

United Nations (UN). (1989). Convention on the Rights of the Child. 20 November 1989,. Retrieved from:http://www.refworld.org/docid/3ae6b38fo.html

United Nations General Assembly (UN). (2010, July). Resolution A/RES/64/292. Retrieved from www.onwa.ca/upload/documents/un-water-as-a-human-right.pdf

United Nations General Assembly (UN). (1989, December 16). International Covenant on Economic, Social, and Cultural Rights. Retrieved from http://www.ohchr.org/EN/ProfessionalInterest/ Pages/CESCR.aspx.

UNFPA, \& Danish Institute for Human Rights (DIHR). (2014). Reproductive rights are human rights: A handbook for national human rights institutions. Retrieved from http://www.ohchr.org/Documents/ Publications/NHRIHandbook.pdf

Warenius, L., Pettersson, K. O., Nissen, E., Hojer, B., Chishima, P., \& Faxelid, E. (2007). Vulnerability and sexual and reproductive health among Zambian secondary school students. Culture, Health, \& Sexuality, 9, 533-544.

Winkler, I. T., \& Roaf, V. (2015). Taking the bloody linen out of the closet: Menstrual hygiene as a priority for achieving gender equality. Cardozo Journal of Law \& Gender, 21, 1-37.

World Health Organization (WHO). (1948). United Nations General Assembly. Retrieved from http://www.who.int/about/definition/en/print.html

Zambia: Public Health Act (ZPHA CAP 295), Section 75. The public health (drainage and latrine) reguent.gov.zm/downloads/VOLUME\%2017.pdf

Zambia Demographic and Health Survey (ZDHS). (2007). Calverton, MD: Micro International 